\title{
Magnetic Fe-Co films electroplated in a deep-eutectic-solvent-based plating bath
}

\author{
T. Yanai, ${ }^{1}$ K. Shiraishi, ${ }^{1, a)}$ Y. Watanabe, ${ }^{1}$ T. Ohgai, ${ }^{1}$ M. Nakano, ${ }^{1}$ K. Suzuki, ${ }^{2}$ \\ and $\mathrm{H}$. Fukunaga ${ }^{1}$ \\ ${ }^{1}$ Graduate School of Engineering, Nagasaki University, Nagasaki 852-8521, Japan \\ ${ }^{2}$ Department of Material Engineering, Monash University, Clayton, Victoria 3800, Australia
}

(Presented 4 November 2014; received 22 September 2014; accepted 4 January 2015; published online 27 April 2015)

\begin{abstract}
We fabricated Fe-Co films from a deep eutectic solvent (DES)-based plating bath and investigated magnetic properties of the plated films. The plating baths were obtained by stirring the mixture of choline chloride, ethylene glycol, $\mathrm{FeCl}_{2} \cdot 4 \mathrm{H}_{2} \mathrm{O}$, and $\mathrm{CoCl}_{2} \cdot 6 \mathrm{H}_{2} \mathrm{O}$. The composition of the plated films depended on the amount of $\mathrm{FeCl}_{2} \cdot 4 \mathrm{H}_{2} \mathrm{O}$ in the plating bath, and $\mathrm{Fe}$ content of the films was varied from 0 to 100 at. \%. Depending on the Fe content, the saturation magnetization and the coercivity of the films varied. The $\mathrm{Fe}_{76} \mathrm{Co}_{24}$ film shows high saturation magnetization and smooth surface, and the change in the saturation magnetization shows good agreement with the expected change by the Slater-Pauling curve. High current efficiency $(>90 \%)$ could be obtained in the wide film composition. From these results, we concluded that the DES-based plating bath is one of effective baths for the Fe-Co films with high current efficiency. (C) 2015 AIP Publishing LLC.
\end{abstract}

[http://dx.doi.org/10.1063/1.4918782]

\section{INTRODUCTION}

Deep eutectic solvents (DESs) have superior industrial advantages, ${ }^{1-4}$ and some of them are attractive to use as a solvent for electroplating of metallic films. In fact, there have been some reports on magnetic films such as $\mathrm{Ni}$, Co, $\mathrm{Ni}-\mathrm{Co}$, Ni-Co-Sn, Sm-Co, and Co-Pt prepared from DESbased baths, ${ }^{3-10}$ and we have also reported $\mathrm{Fe}$ and $\mathrm{Fe}-\mathrm{Ni}$ films prepared in DES-based plating baths. ${ }^{11,12}$ In our previous studies, we confirmed that the plating processes from the DES-based baths for the $\mathrm{Fe}$ and the $\mathrm{Fe}-\mathrm{Ni}$ films have high current efficiency ( $>90 \%$ ). As high current efficiency of the plating processes for $\mathrm{Ni}$ films were also reported by Motoyama et al., ${ }^{13}$ the DES is one of hopeful solvents for the magnetic films. In present study, we focused on $\mathrm{Fe}-\mathrm{Co}$ alloys. The Fe-Co alloys are attractive materials for electric devices due to their high saturation magnetization. Although many studies on Fe-Co films prepared from aqueous solutions have been carried out, the reported values of the current efficiency were relatively low (60\%-90\%). ${ }^{14-16}$ From our results for the $\mathrm{Fe}$ and the $\mathrm{Fe}-\mathrm{Ni}$ films prepared from the DES-based bath, we expected to obtain high current efficiency for the Fe-Co films by using the DES in a plating process. In this study, we plated Fe-Co films from DESbased bath and investigated the magnetic properties of the films and the current efficiency for the plating process.

\section{EXPERIMENTAL PROCEDURES}

\section{A. Electroplating of Fe-Co films}

Some types of DES have been reported, ${ }^{9,17-19}$ and we used a DES base on choline chloride $\left(\mathrm{HOCH}_{2} \mathrm{CH}_{2} \mathrm{~N}\left(\mathrm{CH}_{3}\right)_{3} \mathrm{Cl}\right)$

\footnotetext{
a) Author to whom correspondence should be addressed. Electronic mail: bb52114222@cc.nagasaki-u.ac.jp
}

and ethylene glycol $\left(\mathrm{HOCH}_{2} \mathrm{CH}_{2} \mathrm{OH}\right)$ in the present study. The DES was prepared by stirring the mixture, which consists of $10 \mathrm{~g}$ of ethylene glycol and $10 \mathrm{~g}$ of choline chloride, at $80^{\circ} \mathrm{C}$ until a homogeneous liquid state was obtained. $\mathrm{FeCl}_{2} \cdot 4 \mathrm{H}_{2} \mathrm{O}$ and $\mathrm{CoCl}_{2} \cdot 6 \mathrm{H}_{2} \mathrm{O}$ were added into this DES. The weight of $\mathrm{FeCl}_{2} \cdot 4 \mathrm{H}_{2} \mathrm{O}$ was changed from 0 to $15 \mathrm{~g}$, and the total weight of the reagents $\left(\mathrm{FeCl}_{2} \cdot 4 \mathrm{H}_{2} \mathrm{O}+\mathrm{CoCl}_{2} \cdot 6 \mathrm{H}_{2} \mathrm{O}\right)$ was kept at $15 \mathrm{~g}$ in this study. We did not use any smoothing agents. The composition of the plating bath is shown in Table I. $500 \mu \mathrm{m}$-thick $\mathrm{Fe}$ and $\mathrm{Cu}$ plates were used as the anode and cathode electrodes, respectively. The distance between the electrodes was set at $20 \mathrm{~mm}$, and we obtained $75-\mathrm{mm}^{2} \mathrm{Fe}-\mathrm{Co}$ films on the $\mathrm{Cu}$ plate. The bath temperature was kept at $100^{\circ} \mathrm{C}$ and no stirring action was taken during the plating. The films were electroplated using a direct current. The current density and the plating time were controlled by a computer-aided dc current source. The plating conditions are shown in Table II.

\section{B. Measurements}

The thicknesses and the hysteresis loops of the electroplated films were measured with a micrometer (Mitutoyo CPM15-25 MJ) and a vibrating sample magnetometer (Tamagawa), respectively. The maximum applied field of approximately $1.6 \mathrm{MA} / \mathrm{m}$ was used for the measurement of $\mathrm{M}-\mathrm{H}$ loops. The saturation magnetization and the coercivity

TABLE I. Composition of the DES-based plating bath.

\begin{tabular}{lc}
\hline \hline Components & Weight $(\mathrm{g})$ \\
\hline $\mathrm{FeCl}_{2} \cdot 4 \mathrm{H}_{2} \mathrm{O}$ & $x$ \\
$\mathrm{CoCl}_{2} \cdot 6 \mathrm{H}_{2} \mathrm{O}$ & $15-x$ \\
Choline chloride & 10 \\
Ethylene glycol & 10 \\
\hline
\end{tabular}


TABLE II. Electroplating conditions.

\begin{tabular}{lc}
\hline \hline Conditions & Value \\
\hline Bath temperature & $100{ }^{\circ} \mathrm{C}$ \\
Current density & $67 \mathrm{~mA} / \mathrm{cm}^{2}$ \\
Plating time & $2-20 \mathrm{~min}$ \\
\hline \hline
\end{tabular}

of the electroplated films were determined from the $\mathrm{M}-\mathrm{H}$ loops. The compositions were analyzed by an energy dispersive X-ray (EDX) spectroscopic system (Hitachi Hightechnologies S-3000). The thickness and the composition of each $75 \mathrm{~mm}^{2}$-film were determined by averaging the values obtained for approximately every $8.5 \mathrm{~mm}^{2}$ ( 9 points). The surface roughnesses of the plated films were measured with a surface roughness measuring machines (Mitutoyo SV-400) and evaluated using calculated average roughness $R_{a}$. The current efficiency was calculated from the actual weight of the electroplated film and the theoretical weight obtained by Faraday's law. For the calculation of the theoretical weight, we used the evaluated film composition.

\section{RESULTS AND DISCUSSION}

Figure 1 shows the thickness as a function of the plating time. The results for the baths with $\mathrm{FeCl}_{2} \cdot 4 \mathrm{H}_{2} \mathrm{O}$ contents of 3 and $7.5 \mathrm{~g}$ were shown in Fig. 1. The thicknesses were increased linearly with increasing the plating time, and we found that the DES-based bath enables us to obtain the Fe-Co thick films as well as the Fe and Fe-Ni films. ${ }^{11,12}$

Figure 2 shows the hysteresis loops of the films electroplated for $20 \mathrm{~min}$ in the baths with various $\mathrm{FeCl}_{2} \cdot 4 \mathrm{H}_{2} \mathrm{O}$ content. As shown in Fig. 2, it is clear that the saturation magnetizations of the films varied with the amount of the $\mathrm{FeCl}_{2} \cdot 4 \mathrm{H}_{2} \mathrm{O}$. This result implies that the composition of the films were varied by the change in the amount of $\mathrm{FeCl}_{2} \cdot 4 \mathrm{H}_{2} \mathrm{O}$. In order to confirm the change in the composition, we evaluated dependence of the $\mathrm{Fe}$ content in the as-plated films on the amount of the $\mathrm{FeCl}_{2} \cdot 4 \mathrm{H}_{2} \mathrm{O}$. Figure 3 shows the $\mathrm{Fe}$ content of the electroplated Fe-Co films as a function of amount of the $\mathrm{FeCl}_{2} \cdot 4 \mathrm{H}_{2} \mathrm{O}$ in the bath. We also

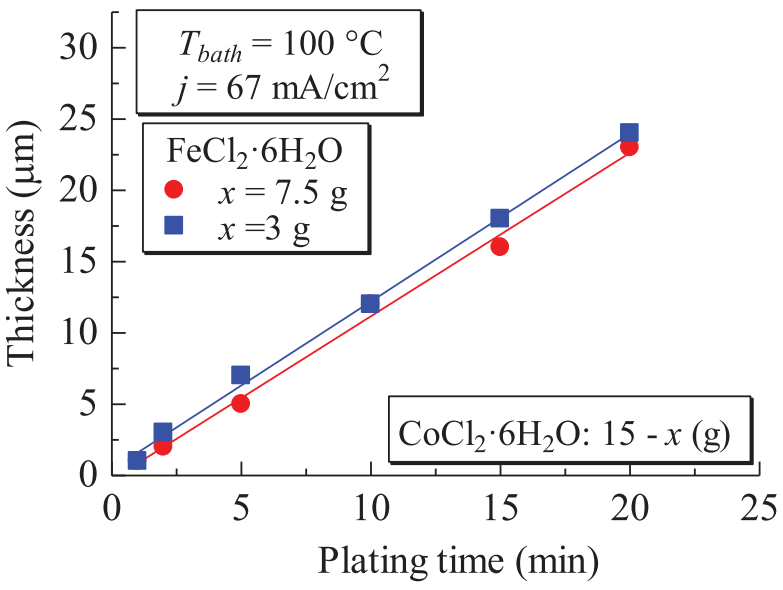

FIG. 1. Thickness of the as-plated Fe-Co films as a function of plating time. The results for the baths with $\mathrm{FeCl}_{2} \cdot 4 \mathrm{H}_{2} \mathrm{O}$ contents of 3 and $7.5 \mathrm{~g}$ were shown in the figure.

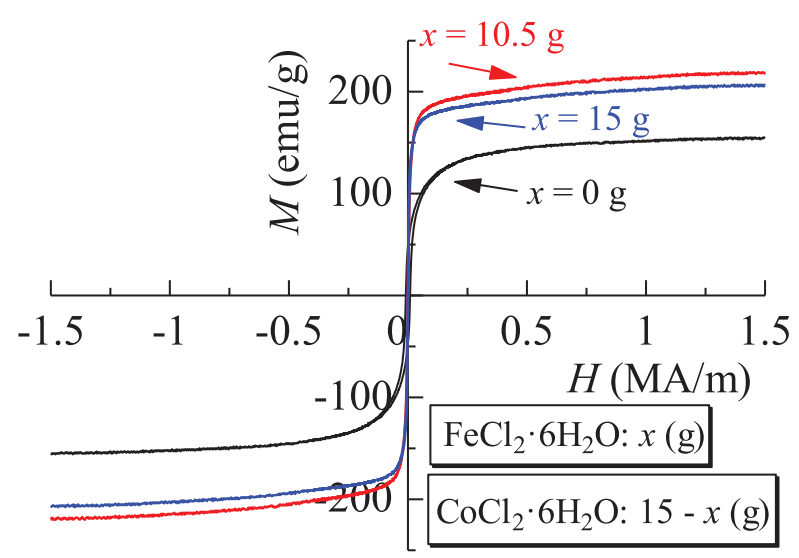

FIG. 2. Hysteresis loops of the Fe-Co films electroplated in the baths with various amount of $\mathrm{FeCl}_{2} \cdot 4 \mathrm{H}_{2} \mathrm{O}$. The films were plated for $20 \mathrm{~min}$.

evaluated the current efficiency and described the result in Fig. 3. The Fe content increased with the amount of the $\mathrm{FeCl}_{2} \cdot 4 \mathrm{H}_{2} \mathrm{O}$, and the current efficiency shows high values $(>90 \%)$ in a wide range of the Fe content. Therefore, it is found that the composition of the Fe-Co films is adjustable by the change in the amount of the $\mathrm{FeCl}_{2} \cdot 4 \mathrm{H}_{2} \mathrm{O}$. We also found that the plating process for the DES-based bath has much higher efficiency compared with those for the aqueous plating baths. ${ }^{14-16}$

We evaluated the effect of the amount of the $\mathrm{FeCl}_{2} \cdot 4 \mathrm{H}_{2} \mathrm{O}$ on magnetic properties of the films in order to investigate the changes in the saturation magnetization against the film composition systematically. Figure 4 shows the changes in the saturation magnetization and coercivity of the electroplated $\mathrm{Fe}-\mathrm{Co}$ films as a function of the Fe content. With increasing the $\mathrm{Fe}$ content from 0 at. \% to approximately 70 at. $\%$, the saturation magnetization increased whereas the coercivity decreased. The maximum saturation magnetization of $220 \mathrm{emu} / \mathrm{g}$ was obtained in the $\mathrm{Fe}_{76} \mathrm{Co}_{24}$ films, and the change in the saturation magnetization shows good agreement with the expected change by the Slater-Pauling curve. The value of $220 \mathrm{emu} / \mathrm{g}$ is slightly smaller than expected one from the Slater-Pauling curve for $\mathrm{Co}_{24} \mathrm{Fe}_{76}$ alloy, indicating that the films include non-magnetic

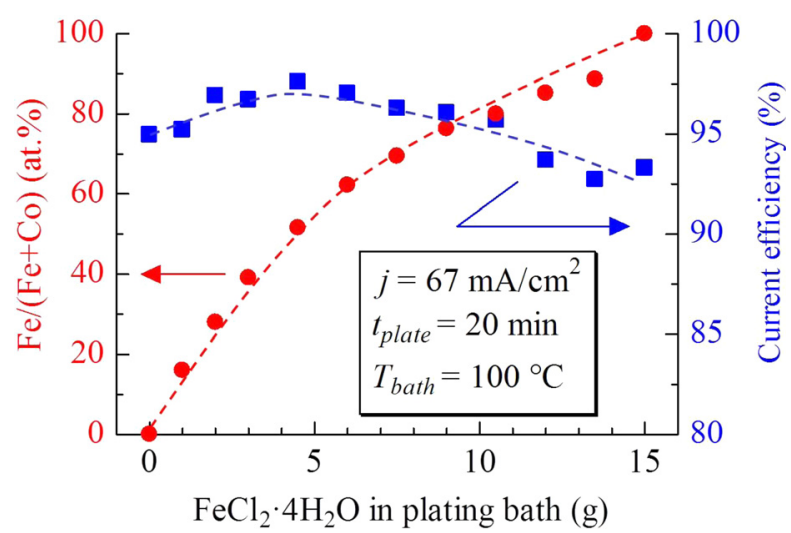

FIG. 3. Fe content of the electroplated Fe-Co films as a function of amount of the $\mathrm{FeCl}_{2} \cdot 4 \mathrm{H}_{2} \mathrm{O}$ in the DES-based plating bath. The films were plated for $20 \mathrm{~min}$, and their thicknesses are almost the same values of approximately $20 \mu \mathrm{m}$. 


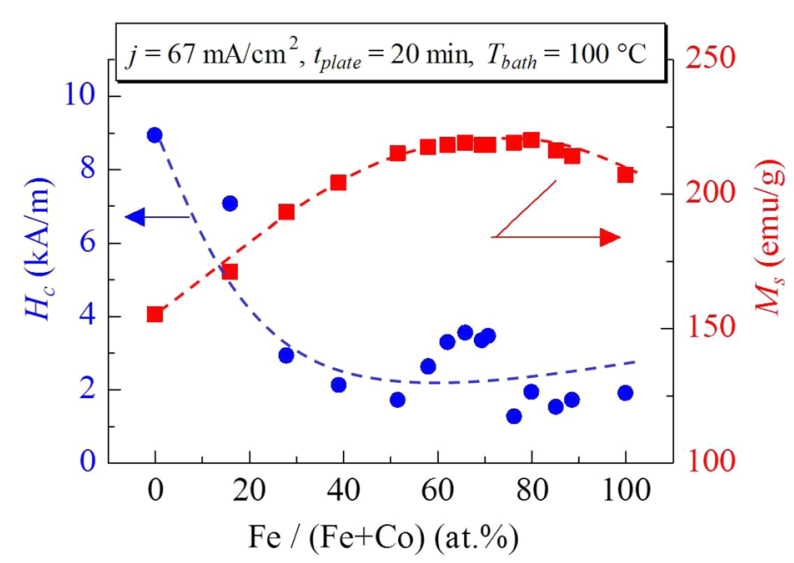

FIG. 4. Coercivity $H_{c}$ and saturation magnetization $M_{s}$ of the electroplated $\mathrm{Fe}-\mathrm{Co}$ films as a function of the Fe content in the film.

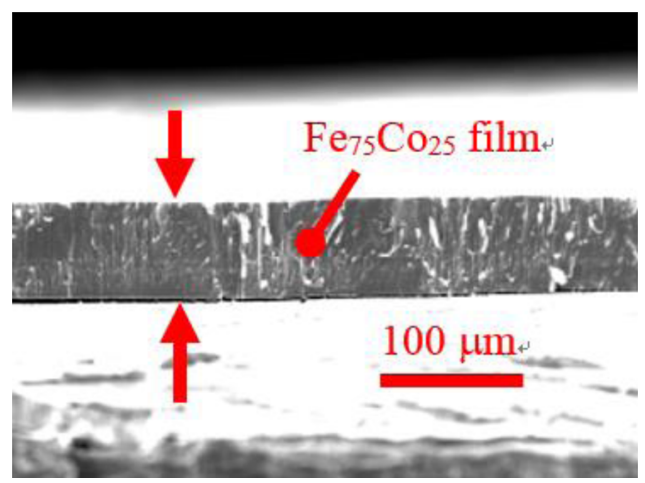

FIG. 5. Cross-sectional SEM image of the $\mathrm{Fe}_{75} \mathrm{Co}_{25}$ film. (a) $\mathrm{Co}$ film, (b) $\mathrm{Fe}$ film, and (c) $\mathrm{Fe}_{76} \mathrm{Co}_{24}$ film.

materials or the densities of the films are low. In order to confirm the film density, we observed the cross-sectional area of the Fe-Co film with the SEM. Figure 5 shows the cross-sectional SEM image of the $\mathrm{Fe}_{75} \mathrm{Co}_{25}$ film. In this experiment, we used $\mathrm{Fe}_{75} \mathrm{Co}_{25}$ thick-film $(\approx 70 \mu \mathrm{m})$ to facilitate the observation. As shown in Fig. 5, the film was not porous. Therefore, we considered that the presence of non-magnetic materials is a factor of the slight difference for the maximum saturation magnetization between the measured value and the expected one.

In general, soft magnetic properties of films with a smooth surface are better than those for films with a rough surface, since a smooth surface does not prevent domain

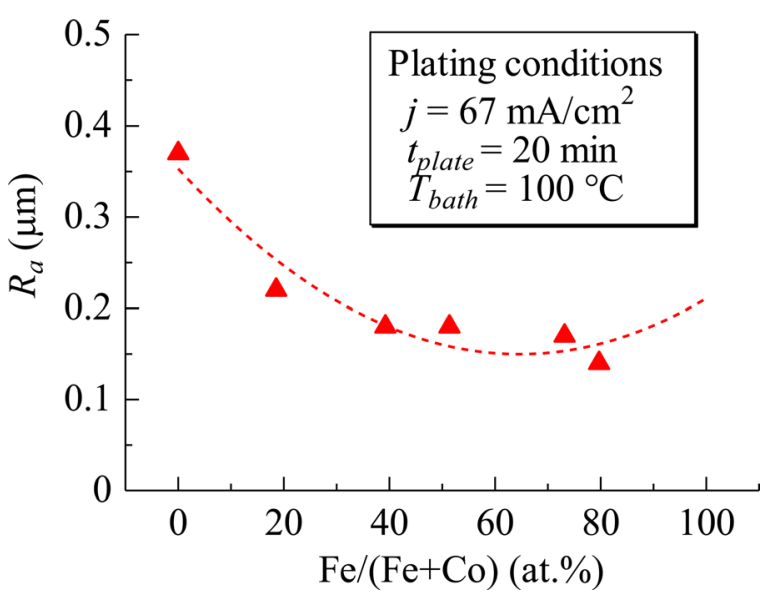

FIG. 7. Calculated average roughness $R_{a}$ of the electroplated $\mathrm{Fe}-\mathrm{Co}$ films as a function of the Fe content in the film.

wall movement during magnetization. Figure 6 shows SEM images of the $\mathrm{Co}, \mathrm{Fe}$, and $\mathrm{Fe}_{76} \mathrm{Co}_{24}$ films. As shown in the SEM images, the surface of the $\mathrm{Fe}_{76} \mathrm{Co}_{24}$ film is much smoother than those for the Co and the Fe films. For quantitative evaluation of the surface roughness, we evaluated the calculated average roughness $R_{a}$ of the Fe-Co films. Figure 7 shows the $R_{a}$ as a function of the Fe content in the film. The small $R_{a}$ values were obtained around the Fe content from 60 at. $\%$ to 80 at. \%, and we considered that the smooth surface is one of factors to show low coercivity in Fig. 4. Zhang et al. have plated Fe-Co thick-films $(\approx 1.5 \mu \mathrm{m})$ from a aqueous plating bath and reported the $\mathrm{Fe}_{66} \mathrm{Co}_{34}$ thick-film with coercivity of $1350 \mathrm{~A} / \mathrm{m}^{20}$ Although $\mathrm{Fe}-\mathrm{Co}$ films prepared from the DES-base bath showed the low coercivity around the Fe content from 60 at. \% to 80 at. \%, the value of approximately $2 \mathrm{kA} / \mathrm{m}$ was slightly higher than that for the aqueous plating bath. ${ }^{19}$ The improvement in the soft magnetic properties is one of our future works.

From above-mentioned results, we concluded that the choline chloride-ethylene glycol based DES is one of effective solvents for electroplating of Fe-Co films due to their high current efficiency.

\section{CONCLUSION}

In this study, we electroplated Fe-Co films in a DESbased bath and investigated the magnetic properties of the films.

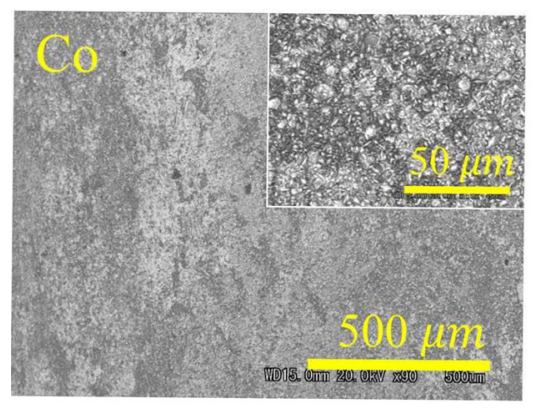

(a) Co film

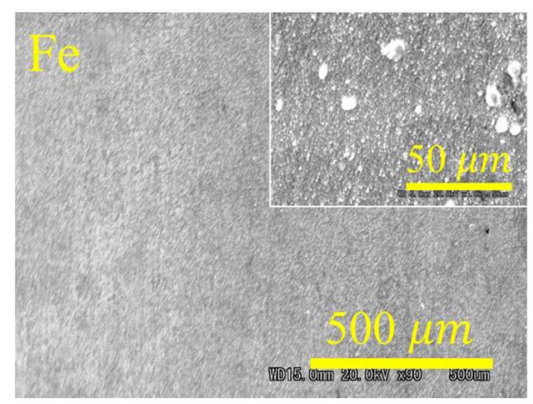

(b) Fe film

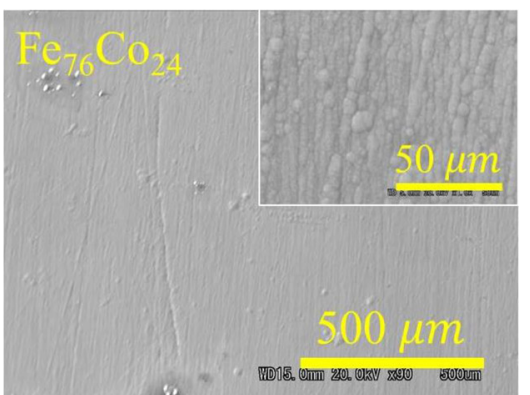

(c) $\mathrm{Fe}_{76} \mathrm{CO}_{24}$ film

FIG. 6. SEM images of the electroplated Co, Fe, and Fe-Co films. 
(1) The Fe content in the electroplated films depended on the amount of the $\mathrm{FeCl}_{2} \cdot 4 \mathrm{H}_{2} \mathrm{O}$ in the plating bath, and adjusting the bath reagent composition is an easy way to control the film composition.

(2) The current efficiency showed high values of over $90 \%$ in a wide range of the Fe content in the plated films.

(3) The highest value of the saturation magnetization of $220 \mathrm{emu} / \mathrm{g}$ was observed in the $\mathrm{Fe}_{76} \mathrm{Co}_{24}$ film, and the change in the saturation magnetization shows good agreement with the expected change by the Slater-Pauling curve.

${ }^{1}$ A. P. Abbott, D. Bothby, G. Capper, D. L. Davies, and R. Rasheed, J. Am. Chem. Soc. 126, 9142 (2004).

${ }^{2}$ A. P. Abbott, G. Capper, D. L. Davies, R. K. Rasheed, and V. Tambyrajah, Chem. Commun. 9, 70 (2003).

${ }^{3}$ A. P. Abbott, G. Capper, D. L. Davies, K. J. McKenzie, and S. U. Obi, J. Chem. Eng. Data 51, 1280 (2006).

${ }^{4}$ E. Gómez, P. Cojocaru, L. Magagnin, and E. Valles, J. Electroanal. Chem. 658, 18 (2011).

${ }^{5}$ P. Cojocaru, L. Magagnin, E. Gómez, and E. Valles, Mater. Lett. 65, 3597 (2011).

${ }^{6}$ H. Yang, X. Guo, N. Birbilis, G. Wu, and W. Ding, Appl. Surf. Sci. 257, 9094 (2011).
${ }^{7}$ P. Guillamat, M. Cortés, E. Vallés, and E. Gómez, Surf. Coat. Technol. 206, 4439 (2012).

${ }^{8}$ G. Saravanan and S. Mohan, J. Alloys Compd. 522, 162 (2012).

${ }^{9}$ Y. H. You, C. D. Gu, X. L. Wang, and J. P. Tu, Surf. Coat. Technol. 206, 3632 (2012).

${ }^{10}$ J. Vijayakumar, S. Mohan, S. A. Kumar, S. R. Suseendiran, and S. Pavithra, Int. J. Hydrogen Energy 38, 10208 (2013).

${ }^{11}$ T. Yanai, T. Shimokawa, Y. Watanabe, T. Ohgai, M. Nakano, K. Suzuki, and H. Fukunaga, J. Appl. Phys. 115, 17A344 (2014).

${ }^{12}$ T. Yanai, K. Shiraishi, Y. Watanabe, T. Ohgai, M. Nakano, K. Suzuki, and H. Fukunaga, IEEE Trans. Magn. 50(11), 2008404 (2014).

${ }^{13}$ M. Motoyama, Y. Fukunaka, T. Sakka, Y. H. Ogata, and S. Kikuchi, ECS Trans. 3, 3 (2007).

${ }^{14}$ H. Kockar, M. Alper, T. Sahin, and O. Karaagac, J. Magn. Magn. Mater. 322, 1095 (2010).

${ }^{15}$ H. Matsushima, Y. Fukunaka, H. Yasuda, and S. Kikuchi, ISIJ 45, 1001 (2005).

${ }^{16}$ C. Qiang, J. Xu, S. Xiao, Y. Jiao, Z. Zhang, Y. Liu, L. Tian, and Z. Zhou, Appl. Surf. Sci. 257, 1371 (2010).

${ }^{17}$ I. Tabakovic, S. Riemer, N. Jayaraju, V. Venkatasamy, and J. Gong, Electrochim. Acta 58, 25 (2011).

${ }^{18}$ A. P. Abbott, G. Capper, K. J. McKenzie, and K. S. Rayder, J. Electroanal. Chem. 599, 288 (2007).

${ }^{19}$ C. D. Gu, Y. H. You, Y. L. Yu, S. X. Qu, and J. P. Tu, Surf. Coat. Technol. 205, 4928 (2011).

${ }^{20}$ Y. Zhang and D. G. Ivey, Mater. Sci. Eng., B 140, 15 (2007). 